\title{
PRODUTIVIDADE E QUALIDADE DO ÓLEO DE LINHAGENS DE AMENDOIM $\left(^{1}\right)$
}

\author{
MARCO ANTONIO TELXEIRA ZULLO $\left({ }^{2}\right)$, IGNÁCIO JOSÉ DE GODOY $\left({ }^{3,6}\right)$, \\ SÉRGIO ALMEIDA DE MORAES $\left({ }^{4,6}\right.$ ) \\ e JOSÉ CARLOS VILA NOVA ALVES PEREIRA ( $\left(^{5}\right)$
}

\begin{abstract}
RESUMO
Visando à obtenção de genótipos de amendoim de elevada produtividade e bom teor de ôleo, sete linhagens, selecionadas para produção de vagens e resistência a doenças, foram escolhidas para avaliação do seu potencial de produção quantitativa e qualitativa de óleo. A produção foi obtida em dois experimentos realizados no campo, em Campinas e Ribeirão Preto, com o delineamento em blocos ao acaso com quatro repetições, testando as linhagens contra um controle conhecido, cultivar Tatu. Avaliaram-se a produção em casca, o rendimento em grãos e o teor de óleo das sementes. Com esses dados, obtidos em cada parcela, estimaram-se os valores de produção de óleo por hectare. A qualidade do óleo foi avaliada pela determinação dos teores dos seguintes ácidos graxos presentes no óleo de amendoim: palmítico, esteárico, oléico, linoléico, araquídico, eicosenóico e beênico. Estimaram-se, ainda, as porcentagens dos ácidos saturados e as razões entre os ácidos oléico e linoléico. Cinco das linhagens apresentaram produções em casca entre 30 e $50 \%$ superiores às do cultivar controle, na média dos dois experimentos. Essa superioridade foi ainda maior entre 46 e $67 \%$, para a variável produção de óleo por hectare, uma vez que as linhagens, de modo geral, apresentaram maiores rendimentos em grãos e maiores teores de óleo do que o cultivar. $O$ óleo das linhagens $21 / 3,21 / 5,21 / 6$, $55 / 9,55 / 16,65 / 3$ e 65/4 apresentou valores significativamente maiores de ácido oléico e da razão ácido oléico/linolćico, o que indica maior resistência do óleo à rancificação.
\end{abstract}

Termos de indexação: amendoim, linhagens, óleo, produção, qualidade.

( ${ }^{\mathrm{I}}$ ) Recebido para publicação em 17 de maio e aceito em 8 de outubro de 1993.

( ${ }^{2}$ Instituto Agronômico (IAC), Seção de Fitoquímica, Caixa Postal 28, 13001-970, Campinas (SP).

$\left({ }^{3}\right)$ Seção de Genética, IAC.

( $\left.{ }^{4}\right)$ Seção de Fitopatologia, IAC.

(5) Estação Experimental de Ribeirão Preto, IAC.

$\left({ }^{6}\right)$ Com bolsa de pesquisa do CNPq. 


\section{ABSTRACT \\ OIL YIELD AND QUALITY OF PEANUT BREEDING LINES}

Seven peanut breeding lincs of the Instituto Agronômico breeding program, selected for pod yield and disease resistance, were evaluated for quantitative and qualitative attributes of oil production. Two field experiments, located at Campinas and Ribeirão Preto Experiment Station, State of São Paulo, Brazil, were carried out, in a complete randomized block design with four replications. The means of each genotype were tested against a known control, cultivar Tatu. In each plot, the following characters were evaluated: pod yield, shelling percentage and seed oil content. Oil yield/ha was estimated from the above data. Oil quality was evaluated by determining the content of the following fatty acids: palmitic, stearic, oleic, linoleic, arachidic, eicosenoic and behenic. The percentage of saturated fatty acids, as well as the oleic/linoleic ratio, were atso estimated. Regarding the yield of pods, five of the breeding lines out-yiclded the control in $30 \%$ to $50 \%$, in the mean of the two experiments. This superiority was even larger, from $46 \%$ to $67 \%$, when the variable oil yield/ha was considered, once additional gains were also observed for shelling percentage and oil content. The oil of lines 21/3, 21/5, 21/6, $55 / 9,55 / 16,65 / 3$ and $65 / 4$ showed average values of oleic acid content and oleic/linoleic ratio significantly higher than those of the control, which indicates a higher resistance to oxidation.

Index terms: peanut, breeding lines, oil, yield, quality.

\section{INTRODUÇÃO}

O amendoim era, até a década de 1970, uma das principais fontes de ólco comestivel no Brasil. Com a expansão da cultura da soja, cujo custo de produção agrícola permitc a obtenção de óleo a um preço menor, a do amendoim foi gradativamente perdendo espaço como espécic oleifera. Essa mudança ocorreu não só no Estado de São Paulo como em outras árcas produtoras da América do Sul (Godoy \& Giandana, 1992).

Em São Paulo, algumas tradicionais regiões produtoras, especialmente a Oeste, tiveram suas áreas de cultivo drasticamente reduzidas c carecem, até hoje, de alternativas agricolas. Nessas regiõcs, que ainda possuem certa estrutura para o processamento e comercialização do produto (máquinas de beneficiamento e indústrias de ólco), o amendoim poderia recuperar parte de sua importância econômica se fosse produzido a um custo menor.

O Instituto Agronômico mantém um programa de melhoramento genético do amendoim, sendo uma de suas linhas de trabalho a seleção de linhagens de elevada capacidade produtiva, resistentes às principais doenças foliares e com porte vcgetativo rastciro, adcquado à col heita totalmente mecanizada. A maior produtividade e um custo menor de produção, pela redução do controle químico das doenças e da mão-de-obra necessária para a colheita, representariam uma possibilidade de aumento da competitividade da cultura, inclusive para a produção de ólco.

Para que se possa avaliar o rendimento cconômico de um cultivar, do ponto de vista de produção de ólco, é recomendável que se cstime a produtividade em óleo por unidade de árca cultivada. Essa estimativa é importante, pois lcva $\mathrm{cm}$ consideração não só a produção em casca como o rendimento em grãos e o teor médio de ólco nas sementes. Embora as variações de teor de óleo entre cultivares sejam proporcionalmente menores do que as diferenças em produção bruta, clas podem contribuir significativamente para diminuir ou aumentar o desempenho de um cultivar quando a produção de ólco/área for considerada (Godoy et al, 1989).

Cobb \& Johnson (1973), numa revisão sobre as propriedades físico-químicas do amendoim, rclatam variações de 44 a $56 \%$ no teor de óleo 
entre cultivares. Nas condições paulistas, Pompeu (1987) obteve um ganho entre 1,4 e $1,7 \%$ no teor de óleo de novos cultivares, com relação ao 'Tatu', comumente plantado no Estado. Godoy et al. (1989) observaram variações entre 43,2 e 50,5\% nas sementes de 14 acessos de germoplasma, teores esses obtidos por ressonância magnética nuclear, na média de seis experimentos, em três locais. Em um desses, as variaçõcs foram de 39,9 a $54,1 \%$. Valores médios de 50,5 contra $47,2 \%$ do cultivar controle significam uma quantidade de óleo $7 \%$ superior, para a mesma quantidade de matéria-prima.

Os óleos vegetais podem variar também $\mathrm{cm}$ qualidade, em função, principalmente, dos tcores dos diversos ácidos que compõcm a sua fração triglicéride. No amendoim, os ácidos olćico c linoléico são os que aparecem em maior proporção, seguidos do palmítico, esteárico e beĉnico. Outros ácidos são encontrados em proporções reduzidas. Os ácidos oléico e linoléico representam ccrca de $80 \%$ do total de ácidos graxos presentes no óleo, sendo, portanto, os principais detcrminantes da sua qualidade (Cobb \& Johnson, 1973).

Os teores dos ácidos olćico c linoléico podem ser utilizados como parâmetros para avaliar a resistência do óleo de amendoim à rancificação. Holley \& Hammons (1968) observaram que há uma correlação negativa entre scus tcores. O oléico é menos insaturado e menos suscctivel à peroxidação. Portanto, maior rclação olćico/ /linoléico indica uma capacidade maior de armazenamento do ólco, sem alteração de suas qualidades

Diversos trabalhos são citados por Ahmed \& Young (1982) e Norden et al. (1987), mostrando a variabilidade genotípica existente $\mathrm{cm}$ amendoim para teores dos diversos ácidos graxos. Nas condições de São Paulo, esse aspecto qualitativo do óleo não tem sido pesquisado.

Visando estudar a possibilidade de obtenção de genótipos que reúnam produtividade $\mathrm{c}$ tcor de óleo acima do observado para as varicdades comerciais atuais, sete linhagens, previamentc sclccionadas para produção de vagens e resistência a doenças, foram escolhidas para avaliação do seu potencial de produção quantitativa e qualitativa de ólco, cujos resultados são aqui relatados.

\section{MATERIAL E MÉTODOS}

Um grupo de vinte linhagens de amendoim (Arachis hypogaea L.) do programa de melhoramento do Instituto Agronômico foi destacado a partir da geração $F_{5}$, por apresentar hábito de crescimento rasteiro, bom potencial de produção de vagens $\mathrm{c}$ resistência parcial à mancha-preta (Cercosporidium personatum). Tais linhagens são resultantes do cruzamento entre o cultivar Tatuí c o accsso $n^{\circ}$ 5239, um germoplasma avaliado como moderadamente resistente à mancha-preta (Moracs et al., 1988).

Essas linhagens foram avaliadas para produtividade comparativa com o controle, cultivar Tatu, cm uma série de ensaios realizados na cstação "das águas", em diversas localidades, durante os anos de 1987/88 a 1990/91. Com base nos resultados dos primeiros anos (dados não publicados), destacaram-se sete linhagens dos ensaios de Campinas e Ribeirão Preto, do ano agrícola 1990/91 para as análises de óleo c demais comparações referentes ao presente trabalho

Os ensaios tiveram o delineamento em blocos ao acaso com quatro repetições. As linhagens foram avaliadas em parcelas de linhas únicas de $5 \mathrm{~m}$ de comprimento, com espaçamento de $70 \mathrm{~cm}$ cntre linhas e densidade de dez plantas/metro, após desbaste de uniformização. Por ser de porte ereto e ciclo mais curto, o 'Tatu' foi plantado em parcelas de três linhas distanciadas de $60 \mathrm{~cm}$, considerando-se como útil a linha central. Os ensaios foram plantados em terrenos previamente calcariados e adubados, no plantio, com $300 \mathrm{~kg} / \mathrm{ha}$ da fórmula 4-14-8. Efetuaram-se, $\mathrm{cm}$ todas as parcelas, durante o ciclo, quatro pulverizaçõcs preventivas para o controle das manchas foliares. O cultivar controle foi colhido aos 100-110 dias do plantio, enquanto as linhagens o foram ao redor de 130 dias. 
Após a colheita e secagem ao sol até peso constante, retiraram-se, de cada parcela, amostras de aproximadamente $300 \mathrm{~g}$ de vagens. Cada amostra foi descascada manualmente e os grãos obtidos, pesados para a determinação do rendimento em grãos, ou seja, a porcentagem do peso em grãos em relação ao peso em casca. Os dados da produção em casca foram multiplicados pelos respectivos rendimentos em grãos de cada parcela, para a estimativa dos valores da produção de grãos em $\mathrm{kg} / \mathrm{ha}$.

As sementes foram submetidas à extração do óleo em soxhlet, por hexano, seguindo determinação gravimétrica do teor de óleo (Triebold \& Aurand, 1963). Os teores de óleo obtidos de cada parcela foram multiplicados pelas respectivas produções de grãos $\mathrm{em} \mathrm{kg} / \mathrm{ha}$ para a obtenção dos valores estimados de produção de óleo em $\mathrm{kg} / \mathrm{ha}$.

Os teores de ácidos graxos foram obtidos por transesterificação (Hartman \& Lago, 1973), seguida de cromatografia em fase gasosa, isotérmica a $180^{\circ} \mathrm{C}$, em coluna de vidro de $6 \mathrm{x}$ $1 / 8$ ", empacotada com DEGS $10 \%$ sobre Chromosorb WAW-DMCS 60-80 mesh, utilizando nitrogênio como gás de arraste e deteç̧ão por ionização de chama (Sawazaki et al., 1987).

Todos os dados foram analisados estatisticamente por localidade e na média das duas localidades, seguindo o delineamento em blocos ao acaso, aplicando-se o teste $F$ para os tratamentos (genótipos), locais e interação genótipo x local. Para todas as variáveis, foram testados os contrastes de cada linhagem contra o cultivar controle, utilizando o teste de Dunnett a 5\%.

\section{RESULTADOS E DISCUSSÃo}

O quadro 1 mostra as produções médias de vagens, de grãos e de óleo, os rendimentos em grãos e os teores de óleo das sementes das sete linhagens e do cultivar Tatu, bem como os resultados das respectivas análises da variância conjuntas para os dois experimentos. Embora os dados tenham sido obtidos de um pequeno número de experimentos, a utilização de um controle, de desempenho conhecido, permite uma avaliação comparativa do potencial de produção de vagens das linhagens. As análises dos valores estimados da produção de grãos e de óleo, em $\mathrm{kg} / \mathrm{ha}$, visa ilustrar as diferenças em produção de óleo por hectare em relação ao cultivar Tatu, scgundo a contribuição dos três componentes aqui considerados: produtividade de vagens, rendimento em grãos no descas- camento e teor de ólco por hectare.

O teste de Dunnett a $5 \%$ de probabilidade detectou diferenças significativas em produção de vagens de cinco das linhagens em relação ao controle. Este produziu $3.215 \mathrm{~kg} / \mathrm{ha}$, na média dos dois experimentos, contra valores que variaram entre 4.193 e $4.825 \mathrm{~kg} / \mathrm{ha}$, ou seja, essas médias excederam à do controle em 30 e $50 \%$, para as linhagens $21 / 6$ e $21 / 5$ respectivamente. As produções das linhagens $55 / 9$ e $65 / 4$ não diferiram estatisticamente do controle.

Observaram-se diferenças significativas em rcndimento de grãos das linhagens 21/3, 21/6, $55 / 16$ c $65 / 3 \mathrm{~cm}$ relação ao cultivar Tatu, que apresentou rendimento de $70,6 \%$, entre os dois experimentos, contra valores que variaram de 75,2 a $77,2 \%$ para as linhagens citadas.

As produções de grãos de todas as linhagens, estimadas a partir dos respectivos rendimentos de grãos, foram significativamente maiores que a do controle, ao nível de $5 \%$. A produção de grãos do 'Tatu' foi de $2.283 \mathrm{~kg} / \mathrm{ha}$, enquanto a das linhagens variou de 2.974 a $3.550 \mathrm{~kg} / \mathrm{ha}$ (para a 65/4 e 21/5 respectivamente), indicando uma supcrioridade entre 30 e $56 \%$ em relação ao controle.

O cultivar Tatu apresentou $50,1 \%$ de óleo nas sementes, na média dos dois experimentos. A análise conjunta detectou diferenças significativas ao nível de $5 \%$ para o teor de óleo de todas as linhagens em relação ao controle. Para estas, os teores variaram entre 51,7\% (para $21 / 6$ ) e $53,8 \%$ (para a $21 / 3$ e $21 / 5$ ). 
Os valores de produtividade em óleo por hectare, estimados a partir das produções de grãos e dos teores de óleo, também foram significativamente superiores para as linhagens em comparação com o controle. Este apresentou 1.140 $\mathrm{kg} / \mathrm{ha}$ de óleo na média dos dois experimentos, contra produções que variaram entre $1.540 \mathrm{c}$ $1.910 \mathrm{~kg} / \mathrm{ha}$ para as linhagens, o que corresponde a uma superioridade entre 35 e $67 \%$ em relação ao controle.

Esses resultados mostram que a vantagem em potencial de produção de vagens das novas linhagens em relação ao cultivar Tatu pode ser acentuada, em decorrência dos ganhos adicionais em rendimento de grãos e teor de óleo, o que resulta em uma superioridade ainda maior quando a variável produção de óleo por hectare é considerada.

Comparando-se os índices relativos das produções de grãos e de óleo das linhagens em relação ao controle (índice 100 ), pode-se avaliar, a partir dos respectivos índices relativos das produções de vagens, a contribuição dos ganhos em rendimento de grãos e do teor de óleo para a superioridade das linhagens em produção de ólco por hectare. Assim, a 65/4, com índice 135 para a produção de óleo por hectare, apresentou o menor acréscimo (11\%) em produtividade, resultante da soma dos ganhos em rendimento e $\mathrm{em}$ teor de óleo, partindo do índice 124 para a produção de vagens. Desses $11 \%$, o rendimento em grãos contribuiu com $6 \%$ e o teor de óleo

Quadro 1. Produtividade em grãos e óleo em diversos genótipos de amendoim

\begin{tabular}{|c|c|c|c|c|c|c|c|c|}
\hline \multirow{2}{*}{ Genótipos } & \multicolumn{4}{|c|}{ Produção } & \multirow{2}{*}{$\begin{array}{l}\text { Rendimento } \\
\text { em grãos }\end{array}$} & \multicolumn{3}{|c|}{ Óleo } \\
\hline & Vagens & \multirow{2}{*}{$\frac{\begin{array}{c}\text { Índice } \\
\text { relativo }\end{array}}{\%}$} & \multirow{2}{*}{$\frac{\text { Grãos }}{\mathrm{kg} / \mathrm{ha}}$} & $\begin{array}{l}\text { Índice } \\
\text { relativo }\end{array}$ & & \multirow{2}{*}{$\frac{\text { Teor }}{g / 100 g}$} & \multicolumn{2}{|c|}{ Produtividade $\begin{array}{c}\text { Índice } \\
\text { relativo }\end{array}$} \\
\hline & $\mathrm{kg} / \mathrm{ha}$ & & & 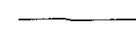 & $\%$ & & $\mathrm{~kg} / \mathrm{ha}$ & $\%$ \\
\hline & \multicolumn{8}{|c|}{ Média $\left({ }^{l}\right)$} \\
\hline Tatu & 3.215 & 100 & 2.283 & 100 & 70,6 & 50,1 & 1.140 & 100 \\
\hline $21 / 3$ & $4.693^{*}$ & 146 & $3.519^{*}$ & 154 & $75,2^{*}$ & $53,8^{*}$ & $1.893^{*}$ & 166 \\
\hline $21 / 5$ & $4.825^{*}$ & 150 & $3.550^{*}$ & 156 & 74,2 & $53,8^{*}$ & $1.910^{*}$ & 167 \\
\hline $21 / 6$ & $4.193^{*}$ & 130 & $3.207^{*}$ & 141 & $76,4^{*}$ & $51,7^{*}$ & $1.660^{*}$ & 146 \\
\hline $55 / 9$ & 4.159 & 129 & $3.063^{*}$ & 134 & 73,9 & $53,1^{*}$ & $1.628^{*}$ & 143 \\
\hline $55 / 16$ & $4.319^{*}$ & 134 & $3.322^{*}$ & 146 & $77,1^{*}$ & $52,7^{*}$ & $1.756^{*}$ & 154 \\
\hline $65 / 3$ & $4.498^{*}$ & 140 & $3.468^{*}$ & 152 & $77,2^{*}$ & $52,0^{*}$ & $1.804^{*}$ & 158 \\
\hline $65 / 4$ & 3.982 & 124 & $2.974^{*}$ & 130 & 75,0 & $51,8^{*}$ & $1.540^{*}$ & 135 \\
\hline Média & $4.235,3$ & & $3.173,1$ & & 74,95 & 52,37 & $1.666,6$ & \\
\hline F (genótipos) & $9,24^{* *}$ & & $8,65^{* *}$ & & $3,33^{* *}$ & $25,53^{* *}$ & $10,34^{* *}$ & \\
\hline F (experimentos) & s) $24,42^{* *}$ & & 2,14 & & $68,00^{* *}$ & $8,85^{* *}$ & 3,11 & \\
\hline $\mathrm{F}$ (interação) & 2,08 & & 1,62 & & 1,86 & $6,17^{* *}$ & 1,78 & \\
\hline $\mathrm{F}$ (tratamentos) & $6,91^{* *}$ & & $4,93^{* *}$ & & $6,96^{* *}$ & $15,38^{* *}$ & $5,86^{* *}$ & \\
\hline s & 464,7 & & 400,9 & & 3,34 & 0,69 & 218,6 & \\
\hline $\mathrm{CV}(\%)$ & 10,97 & & 12,64 & & 4,45 & 1,32 & 13,12 & \\
\hline Dunnett $5 \%$ & 968,1 & & 579,4 & & 4,82 & 1,00 & 315,9 & \\
\hline
\end{tabular}

( $\left.{ }^{1}\right)$ Médias de dois experimentos com quatro repetições por experimento. ${ }^{*},{ }^{* *}$ : valores significativos a p $>95 \%$ e $\mathrm{p}>99 \%$. 
com 5\%. O maior acréscimo (27\%) foi observado na linhagem $21 / 5$, onde $16 \%$ podem ser atribuídos ao ganho em rendimento de grãos e $11 \%$ ao maior teor de óleo nas sementes.

Ao nível de agricultor, a superioridade das linhagens em produção de vagens pode representar uma compensação para os menores preços normalmente pagos pela indústria de óleo em relação aos valores do amendoim comercializado para consumo como alimento. Além disso, a própria indústria poderia beneficiar-se com o maior rendimento em grãos e maior teor de ólco, o que representaria uma vantagem adicional quc, pclos presentes dados, poderia atingir 11 a $27 \%$ sobre a produção comercializada de 1 ha.

Os óleos obtidos dos diversos genótipos de amendoim foram analisados quanto aos seus tcores $\mathrm{em}$ ácidos graxos, tendo sido possível identificar, $\mathrm{cm}$ todas as amostras, os ácidos palmítico, estcárico, oléico, linoléico, araquídico, cicosenóico e beênico (Quadro 2).

De modo geral, os tcores desses ácidos foram dependentes do genótipo, à exceção do palmítico. Este, o oléico e o linoléico corresponderam a cerca de $90 \%$ dos ácidos graxos no óleo de amendoim.

Quadro 2. Composição em ácidos graxos de ólcos obtidos de diversos genótipos de amendoim em duas localidades

Genótipos $\quad \Lambda$ cidos graxos

Ácidos Razão

Palmítico Esteárico Oléico Linoléico Araquídico Eicosenóico Beênico saturados $\mathrm{O} / \mathrm{L}\left({ }^{1}\right)$

\begin{tabular}{|c|c|c|c|c|c|c|c|c|c|}
\hline \multirow[b]{2}{*}{ Tatu } & \multicolumn{9}{|c|}{$\operatorname{Mćdia}\left({ }^{2}\right)$} \\
\hline & 12,68 & 2,71 & 38,18 & 40,20 & 1,18 & 1,45 & 3,61 & 20,16 & 0,96 \\
\hline $21 / 3$ & 14,07 & 2,40 & $46,85^{*}$ & $30,47^{*}$ & 1,03 & 1,49 & 3,69 & 21,20 & $1,55^{*}$ \\
\hline $21 / 5$ & 13,05 & 2,01 & $50,29^{*}$ & $28,83^{*}$ & 1,11 & 1,43 & 3,27 & 19,45 & $1,76^{*}$ \\
\hline $21 / 6$ & 12,84 & 2,51 & $45,73^{*}$ & $31,03^{*}$ & 1,54 & $1,82^{*}$ & $4,54^{*}$ & 21,42 & $1,55^{*}$ \\
\hline $55 / 9$ & 13,32 & 2,52 & $45,12^{*}$ & $32,16^{*}$ & 1,36 & $1,75^{*}$ & 3,78 & 20,97 & $1,43^{*}$ \\
\hline $55 / 16$ & 12,86 & 2,26 & $48,25^{*}$ & $29,61^{*}$ & 1,21 & $1,66^{*}$ & 4,15 & 20,48 & $1,68^{*}$ \\
\hline $65 / 3$ & 13,09 & 2,00 & $46,46^{*}$ & $31,79^{*}$ & 0,97 & $1,84^{*}$ & 3,86 & 19,91 & $1,47^{*}$ \\
\hline $65 / 4$ & 12,87 & 2,38 & $44,69^{*}$ & $32,39^{*}$ & 1,32 & $1,96^{*}$ & 4,38 & 20,96 & $1,38^{*}$ \\
\hline Média & 13,10 & 2,35 & 45,70 & 32,06 & 1,21 & 1,67 & 3,91 & 20,57 & 1,47 \\
\hline F (genótipos) & 0,59 & $2,88^{*}$ & $7,49^{* *}$ & $9,94^{* *}$ & $4,61^{* *}$ & $4,57^{* *}$ & $5,19 * *$ & 1,06 & $5,83^{* *}$ \\
\hline F (experimentos) & $12,33^{* *}$ & $15,25 * *$ & $8,84^{* *}$ & 0,17 & $40,18^{* *}$ & $166,17^{* *}$ & $275,35^{* *}$ & $10,68^{* *}$ & $2,81^{* *}$ \\
\hline F (interação) & 0,47 & 1,68 & 0,89 & 1,38 & $2,63^{*}$ & 0,26 & 1,23 & 1,02 & 1,06 \\
\hline F (tratamentos) & 1,32 & $3,14^{* *}$ & $4,50^{* *}$ & $5,29^{* *}$ & $6,06^{* *}$ & $13,33^{* *}$ & $21,35^{* *}$ & 1,68 & $3,40^{* *}$ \\
\hline $\mathrm{s}$ & 1,63 & 0,41 & 3,65 & 3,15 & 0,25 & 0,26 & 0,52 & 1,88 & 0,29 \\
\hline CV (\%) & 12,42 & 17,59 & 7,99 & 9,84 & 20,24 & 15,77 & 13,42 & 9,16 & 19,39 \\
\hline Dunnett $5 \%$ & 1,61 & 0,77 & 4,98 & 5,35 & 0,58 & 0,19 & 0,84 & 2,75 & 0,42 \\
\hline
\end{tabular}

( $\left.{ }^{1}\right)$ Razão entre os teores dos ácidos oléico e linoléico. $\left({ }^{2}\right)$ Médias de dois experimentos com quatro repetições por experimento. *, **: valores significativos a $p>95 \%$ e $p>99 \%$. 
Os teores de ácido palmítico não se mostraram dependentes do genótipo e corresponderam, em média, a $13,1 \%$ dos ácidos graxos. Os teores dos ácidos esteárico, araquídico e beênico se mostraram dependentes do genótipo e corresponderam, respectivamente, em média, a 2,35 , 1,21 e 3,91\%, dos ácidos graxos do óleo obtido em ambos os experimentos. Apesar disso, o teor de ácidos graxos saturados (a soma dos teores dos ácidos palmítico, esteárico, araquídico e beênico) - que foi de $20,57 \%$ em média - não se mostrou dependente do genótipo, em função de o ácido palmítico representar cerca de $64 \%$ desta fração e de se mostrarem negativas as correlações entre o ácido palmítico e os ácidos esteárico $\left(r=-0,4881^{*}\right)$, araquídico $\left(r=-0,5235^{*}\right)$ e beênico ( $\left.r=-0,7492^{* *}\right)$ - Quadro 3 .

Quanto aos ácidos graxos insaturados (oléico, linoléico e eicosenóico), observou-se que seus teores, individualmente, foram dependentes do genótipo e corresponderam, respectivamente, a. $45,70,32,06$ e $1,67 \%$ em média. Todos os novos genótipos apresentaram teores significativamente maiores de ácido oléico e menores de linoléico do que o 'Tatu', o que provocou razões oléico/li- noléico significativamente maiores para as linhagens em relação ao cultivar de referência. A razão oléico/linoléico, parâmetro diretamente proporcional à estabilidade do óleo de amendoim (Ahmed \& Young, 1982), mostrou-se dependente dos genó-tipos utilizados. Embora os valores dessa razão aqui verificados se situem na faixa de 1,0 a 4,0, normalmente encontrada para o amendoim (Ahmed \& Young, 1982; Norden et al., 1987), elas são, para os novos genótipos, significativamente superiores às encontradas para o cultivar. Tatu, o que as torna produtoras de óleo de amendoim de maior estabilidade que o obtido do cultivar de referência. Os teores de ácido eicosenóico das linhagens $21 / 3$ e 21/5 foram indistintos do apresentado pelo cultivar Tatu.

Foram observadas, no conjunto de ambos os experimentos, correlações significativas (Quadro $3)$ entre os teores dos ácidos graxos superiores $\left(r=0,6970^{* *}\right.$ entre araquídico e eicosenóico; $r$ $=0,8027^{* *}$ entre araquídico e beênico, e $\mathrm{r}=$ $0,9529 * *$ entre eicosenóico e beênico). Observou-se uma correlação negativa e significativa entre os teores de ácidos oléico e linoléico ( $\mathrm{r}=$ $\left.-0,9119^{* *}\right)$

Quadro 3. Correlações lineares entre teor de óleo e de ácidos graxos em diversos genótipos de amendoim

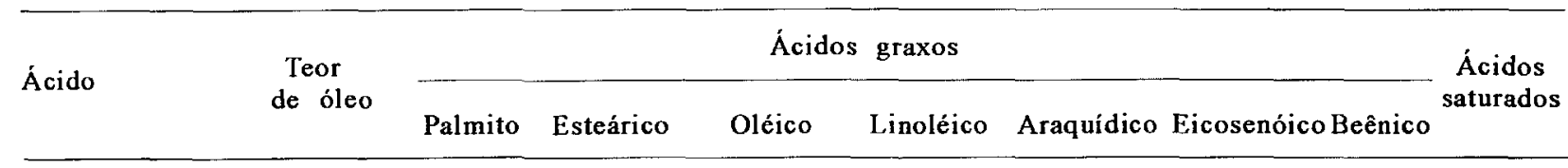

\begin{tabular}{|c|c|c|c|c|c|c|c|c|}
\hline Palmítico & $-0,0071$ & & & & & & & \\
\hline Esteárico & $-0,1314$ & $-0,4881^{*}$ & & & & & & \\
\hline Oléico & $0,5998^{*}$ & 0,4151 & $-0,6546^{* *}$ & & & & & \\
\hline Linoléico & $-0,6479 * *$ & $-0,2560$ & 0,4070 & $-0,9119^{* *}$ & & & & \\
\hline Araquidico & $-0,1032$ & $-0,5235^{*}$ & $0,6487^{* *}$ & $-0,3502$ & $-0,0017$ & & & \\
\hline Eicosenóico & 0,1043 & $-0,7608^{* *}$ & 0,4979 & $-0,3330$ & $-0,0082$ & $0,6970^{* *}$ & & \\
\hline Beênico & 0,0529 & $-0,7492^{* *}$ & $0,5857^{*}$ & $-0,3665$ & $-0,0028$ & $0,8027^{* *}$ & $0,9529^{* *}$ & \\
\hline Saturados & $-0,0182$ & $-0,2542$ & $0,6684^{* *}$ & $-0,3289$ & $-0,0770$ & $0,8390^{* *}$ & $0,6842^{* *} \quad 0,7927^{* *}$ & \\
\hline Razão $O / L\left({ }^{1}\right)$ & $0,5401^{*}$ & 0,3689 & $-0,5221^{*}$ & $0,9577^{* *}$ & $-0,9608^{* *}$ & $-0,1124$ & $-0,2187$ & $-0,0948$ \\
\hline
\end{tabular}

( $\left.{ }^{1}\right)$ Razão entre os teores dos ácidos oléico e linoléico. $\left({ }^{2}\right)$ Médias de dois experimentos com quatro repetições por experimento. ${ }^{*},{ }^{* *}$ : valores significativos a $\mathrm{p}>95 \%$ e $\mathrm{p}>99 \%$. 


\section{CONCLUSÕeS}

1. Das linhagens avaliadas para produção em casca, destacaram-se a 21/3,21/5, 21/6, 55/16 e $65 / 3$, com produções superiores à do cultivar Tatu, na média dos experimentos realizados, variando entre 30 e $50 \%$.

2. Os maiores valores de rendimentos $\mathrm{em}$ grãos e teor de óleo observados nas linhagens $21 / 3,21 / 5,21 / 6,55 / 16$ e $65 / 3$ contribuíram positivamente para uma vantagem ainda maior $\mathrm{cm}$ relação ao cultivar Tatu, quando sc considerou a variável produção de óleo por hectarc. Essa vantagem passou a ser de 46 a $67 \%$, com o cultivo dessas linhagens, o que representa a possibilidade de uma significativa redução no custo final de produção do óleo para a cultura do amendoim.

3. A avaliação do teor de ácidos graxos do óleo mostrou que as linhagens 21/3, 21/5, $21 / 6,55 / 9,55 / 16,65 / 3$ e 65/4 apresentaram tcores de ácido oléico significativamente superiores c de ácido linoléico, significativamente inferiores aos do cultivar Tatu, na média dos dois experimentos. Todas as linhagens foram superiores ao controle, na média dos dois ensaios para a razão ácido oléico/ácido linoléico, variávcl utilizada como indicativa da maior estabilidade do óleo à rancificação.

\section{REFERÊNCIAS BIBLIOGRÁFICAS}

AHMED, E. M. \& YOUNG, C. T. Composition, quality, and flavor of peanuts. In: PATEE, H.E. \& YOUNG, C.T., eds. Peanut science and technology. Yoakum, Texas, American Peanut Research and liducation Society, 1982. chap.17, p.655-688.
COBB, W. Y. \& JOHNSON, B. R. Physicochemical properties of peanuts. In: LELLANDS, T.E. ed., Peanuts: culture and uses. Stillwater, Oklahoma. American Peanut Research and Education Association. 1973. chap.6, p. 209-263.

GODOY I.J. \& GIANDANA, E.H., Groundnut production and research in South America. In: NIGAM, S.N., ed. Groundnut a global perspective: proceedings of an international workshop. International Crops Research Institute for the Semi-Arid Tropics Patancheru, India, 1992. p.77-85.

GODOY, I. J. de; PEREIRA, J. C. V. N. A. \& MARTINS, A. L. M. Capacidade de produção de grãos e óleo em linhagens e cultivares de amendoim. Bragantia, Campinas, 48(1):27-38, 1989.

IIARTMAN, L. \& LAGO, R. C. A. Rapid preparation of fatty acid methyl esters from lipids. Laboratory Practice, London, 22: 475-477, 1973.

IIOLLEY, K. T. \& HAMMONS, R. O. Strain and seasonal effects on peanut characteristics. Athens, University of Georgia - College of Agriculture Experiment Stations, 1968. 27p. (Research bulletin, 32)

MORAIS, S. A. de; GODOY, I. J. de; GERIN, M. A. N.; PLDRO JÚNIOR, M. J. \& PEREIRA, J. C. V. N. A. I:pidemiologia de Cercosporidium personatum em genótipos de amendoim. Fitopatologia Brasileira, Brasília, 13(3): 255-260, 1988.

NORDEN, $\Lambda$. J.; GORBET, D. W.; KNAUFT, D. A. \& YOUNG, $C$. T. Variability in oil quality among peanut genotypes in the Florida breeding program. Peanut Science, Raleigh, 14(1):7-11, 1987.

POMPEU, A. S. IAC-Oirã, IAC-Poitara e IAC-Tupã: novos cultivares de amendoim para o Estado de São Paulo. Bragantia, Campinas, 46(1):127-131, 1987. (Nota)

SAW $7 \Lambda K I$, II. E.; TEIXEIRA, J. P. F. \& MIRANDA, M. $\Lambda$. C. de. $\Lambda$ valiação da atividade da lipoxigenase em linhagens de soja. Bragantia, Campinas, 46(2):371$-380,1987$.

TRIIBBOLD, II. O. \& AURAND, L. W. General procedures and methods used in food analysis. In: TRIEBOL.D, H. O. \& AURAND, L.W. Food composition and analysis. New York, Van Nostrand, 1963. chap. 2, p. 9-37. 